\title{
CHANGES IN MACULAR THICKNESS AFTER PART TIME OCCLUSION IN CHILDREN WITH AMBL YOPIA USING OPTICAL COHERENCE TOMOGRAPHY (OCT)
}

By

\section{Mohamed Zakaria Eid, Ahmed Mahmoud Amin and Mahmoud El-Sayed Mohamed}

Department of Ophthalmology, Faculty of Medicine, Al-Azhar University, Cairo, Egypt

Correspondence to: Mahmoud Elsayed Mohamed.

Email: mahmoudsalem3330@gmail.com, Telephone: 01009613330

\begin{abstract}
Background: Amblyopia is the commonest childhood vision disorder, most children with amblyopia require refractive correction as well as patching; Evidences for direct retinal changes in amblyopic eyes are still inconclusive and controversial.

Objectives: To detect changes in the macula by macular Optical Coherence Tomography (OCT) after part time occlusion in children with amblyopia.

Patients and Methods: Arandomised non controlled study included forty child suffering amblyopia in this study. Best corrected visual acuity (BCVA: 0.1-0.5) were recruited and treated with refractive correction, and part time occlusion (6 hours/day) for one week per year. BCVA and macular thickness were measured by OCT before and after treatment. Factorial repeated-measures analysis of variance was performed to determine the macular thickness in amblyopic eyes changed after amblyopia treatment.

Results: The mean age of children was $8.57 \pm 2.52$ years. There was a statistically significant difference in the central macular thickness pre $\&$ post amblyopia treatment. There was no statistically significant difference for the other macular thickness parameters except for superior quadrant of parapovea where the difference was significantly significant.

Conclusion: The mean of central macular thickness and superior quadrant of parapovea increased after part time occlusion treatment compared to pretreatment. No significant difference in average macular thickness, (nasal, temporal, inferior) parapovea, perifovea, retinal nerve fiber layer (RNFL) thickness and ganglion cell layer (GCL) before and after treatment.
\end{abstract}

Keywords: Amblyopia, occlusion therapy, macular changes.

\section{INTRODUCTION}

Strabismic amblyopia results from abnormal binocular interaction where there is continued monocular suppression of the deviating eye. Bilateral ametropic amblyopia results from high symmetrical refractive errors, usually herpermetropia.
Meridional amblyopia results from image blur in one meridian, e.g. uncorrected astigmatism. In absence of organic lesion, a difference in best corrected visual acuity of two snellen lines or more (or $<1 \log$ unit) is indicative of amblyopia (Bowling , 2016). 
The part-time occlusion treatment in school-aged amblyopes, which had been carried out after school hours, was successful and the effect was sustained in most cases (Hwang et al., 2010).

Optical coherence tomography (OCT) uses a continuously emitting optically coherent laser diode centered at $850 \mathrm{~nm}$ and focused at the retina. The superluminance low-coherence diode emits light with a 20 to $25 \mathrm{~nm}$ band width. For thickness measurements, the time delay of reflected or backscattered light is determined using coherence interferometry (Liu et al., 2010).

Evidences for direct retinal changes in amblyopic eyes are still inconclusive and controversial, although electroretinograms elicited by patterned stimuli in humans with various types of amblyopia were found to be significantly reduced. Studies using optical coherence tomography (OCT) imaging of the retina have not produced definite results (Sapkota et al., 2014).

The purpose of this study was to determine macular changes by OCT after part time occlusion treatment in children with amblyopia.

\section{PATIENTS AND METHODS}

Arandomised non controlled study included forty child aged 5-12 years at the outpatient clinic, El Mattarya Teaching Hospital and Al-Hussein University Hospital, Cairo, Egypt. The study protocol was adhered to the tents of declaration of Heliniski and was approved by the ethical committee of the Faculty of Medicine, AlAzhar University.

\section{Inclusion criteria:}

We included in the study children with BCVA in the amblyopic eye was 0.1 to 0.5 by decimal system after conversion from snellen chart; Intereye acuity difference was 2 Snellen lines. No amblyopia treatment (other than spectacles) in the past month and no more than 1 month of amblyopia treatment in the past 6 months.

\section{Exclusion criteria:}

In the study we excluded children with history of seizures, prematurity (birth weight $<1500 \mathrm{~g}$ or gestational age $<34$ weeks), mental retardation, ocular anomalies or pathologies, fundus lesions, nystagmus, glaucoma, organic lesions and history of intraocular surgery.

The patient hos undergon complete eye examination ,BCVA testing with Snellen chart including crowding phenomenon and neutral denisty filter before and after part time occlusion treatment with patching (6 hours/day) for one week per year, evaluation of ocular duction and versions, alternate prism cover test for diagnosis and measurement of eye deviation, cycloplegic refraction (automated) $45 \mathrm{~min}$ after installing cyclopentolate $1 \%$, one drop 10 min apart, anterior segment examination by slit lamp, IOP measurement with air puff tonometer, funduscopy to rule out optic nerve and macular lesions . 3D retinal topography of amblyopic eye of each participante was done before and after patching using topcon $3 \mathrm{~d}$ oct 2000 fa plus machine (made in Japan).

The mean of these values, as calculated by preloaded software was used to calculate the average macular thickness, 


\section{CHANGES IN MACULAR THICKNESS AFTER PART TIME OCCLUSION...}

central macular thickness, total volume, parafoveal quadrants, perifoveal quadrants, RNFL thickness and GCL.

Recorded data were analyzed using the statistical package for social sciences, version 20.0 (SPSS Inc., Chicago, Illinois, USA). Quantitative data were expressed as mean \pm standard deviation (SD). Qualitative data were expressed as frequency and percentage. Paired sample t-test of significance was used when comparing between related samples. The confidence interval was set to $95 \%$ and the margin of error accepted was set to 5\%. So, the Probability (p-value) was considered significant as the following: Pvalue $<0.05$ was considered significant, $P$ value $<0.001$ was considered as highly significant and P-value >0.05 was considered insignificant.

\section{RESULTS}

The present study included $19(47.5 \%)$ females and $21(52.5 \%)$ males. The mean age was $8.57 \pm 2.52$. The main complain in the study group was diminution of vision in 32 patient $(80 \%)$, and eye deviation in 8 patients $(20 \%)$. Considering refraction of the study group, myopic patients were $26(65 \%)$ with a mean $-7.07 \pm 4.55$, While hyperopic patients was $14(35 \%)$ with a mean $3.93 \pm 1.96$ (Table 1).

\section{Table (1): Refraction distribution of the study group}

\begin{tabular}{|l|c|c|c|c|}
\hline Refraction & No. & \% & Range & Mean \pm SD \\
\hline Myopia & 26 & $65.0 \%$ & -16.75 to -1 & $-7.07 \pm 4.55$ \\
\hline Hypermetropia & 14 & $35.0 \%$ & 1 to 8 & $3.93 \pm 1.96$ \\
\hline Total & 40 & $100.0 \%$ & -16.75 to 8 & $-3.22 \pm 6.51$ \\
\hline
\end{tabular}

In the study group, the right eye was amblyopic in $21(52.5 \%)$ patients, while the left eye was the affected in $19(47.5 \%)$ patients. Considering BCVA, we found a statistically significant difference when compared pre - and post - amblyopia treatment (Table 2).

Table (2): Comparison between BCVA before and after treatment

\begin{tabular}{|l|c|c|c|c|c|}
\hline \multirow{2}{*}{ BCVA } & \multirow{2}{*}{ Range } & \multirow{2}{*}{ Mean \pm SD } & \multirow{2}{*}{ Mean Diff. } & \multicolumn{2}{|c|}{ Mann-Whitney test } \\
\cline { 1 - 2 } & & & & p-value \\
\hline Before & $0.1-0.5$ & $0.27 \pm 0.12$ & \multirow{2}{*}{0.22} & & $<0.001$ \\
\hline After & $0.1-1$ & $0.49 \pm 0.20$ & & & $<$ \\
\hline
\end{tabular}

Fundus examination was normal in 32 $(80 \%)$, tigroid in $4(10 \%)$, tigroid with tilted disc in $3(7.5 \%)$ and tigroid with mylenated nerve fibers in $1(2.5 \%)$. Two of our patients suffered alternating exotropia $(5 \%)$ and 8 patients suffered esotropia (fully accommodative) (20\%). There was a statistically significant difference in the central thickness when compared pre - and post - amblyopia treatment, while the difference was statistically non-significant in average macular thickness and total volume There was a statistically significant difference in the superior quadrant of parafovea when compared pre - and post amblyopia treatment, while the difference was statistically non-significant in other quadrants of parafovea There were statistically non-significant differences in 
all quadrants when compared pre - and post - amblyopia treatment (Table 3). Considering RNFL thickness, GCL+ and GCL++, we found statistically non- significant differences when compared pre - and post - amblyopia treatment (Table $3)$.

Table (3): Pre-treatment VS. post-treatment OCT macula

\begin{tabular}{|l|c|c|c|c|}
\hline \multirow{2}{*}{ Treatment } & \multirow{2}{*}{$\begin{array}{c}\text { Before } \\
\text { parameters }\end{array}$} & \multirow{2}{*}{$\begin{array}{c}\text { After } \\
\text { Treatment }\end{array}$} & Treatment & \multicolumn{2}{c|}{ Paired Sample t-test } \\
\cline { 4 - 5 } & & & & Mean Diff. \\
p-value \\
\hline Average Thickness & $267.65 \pm 20.60$ & $268.40 \pm 21.28$ & 0.750 & 0.525 \\
\hline Central Thickness & $188.30 \pm 28.33$ & $195.08 \pm 33.88$ & 6.780 & $0.038^{*}$ \\
\hline $\begin{array}{l}\text { Total Volume } \\
\text { Parafovea Macula }\end{array}$ & $7.49 \pm 0.81$ & $7.61 \pm 0.62$ & 0.120 & 0.118 \\
Nasal & $294.20 \pm 24.95$ & $297.63 \pm 23.45$ & 3.430 & 0.064 \\
\hline Superior & $292.25 \pm 26.72$ & $297.45 \pm 23.23$ & 5.200 & $0.049^{*}$ \\
\hline Temporal & $281.20 \pm 21.55$ & $285.13 \pm 27.16$ & 3.930 & 0.216 \\
\hline $\begin{array}{l}\text { Inferior } \\
\text { Perifovea Macula }\end{array}$ & $291.65 \pm 25.15$ & $292.53 \pm 24.83$ & 0.880 & 0.666 \\
Nasal & $277.20 \pm 30.65$ & $277.28 \pm 32.45$ & 0.080 & 0.938 \\
\hline Superior & $264.83 \pm 20.44$ & $264.70 \pm 22.81$ & -0.130 & 0.942 \\
\hline Temporal & $250.00 \pm 23.52$ & $251.60 \pm 23.74$ & 1.600 & 0.237 \\
\hline Inferior & $258.70 \pm 28.17$ & $261.33 \pm 25.93$ & 2.630 & 0.479 \\
RNFL Thickness & $31.65 \pm 2.18$ & $32.00 \pm 2.31$ & 0.350 & 0.264 \\
\hline GCL+ & $71.00 \pm 3.49$ & $71.18 \pm 3.57$ & 0.180 & 0.138 \\
\hline GCL++ & $102.03 \pm 4.25$ & $102.78 \pm 4.21$ & 0.750 & 0.235 \\
\hline
\end{tabular}

\section{DISCUSSION}

The mainstay treatment for amblyopia is occlusion of the better eye by an opaque patch ("patching"), to promote visual function. Part-time occlusion, defined as occlusion for 2-6 hours per day, has been shown to achieve results similar to those of prescribed full-time occlusion. The relative duration of patch-on and patch-off intervals should reflect the degree of amblyopia, maintenance patching of 1- 2 hours per day is often prescribed to prevent recurrence of amblyopia after successful patching.

By examination of forty amblyopogenic patients, we performed pretreatment OCT macula, part time occlusion treatment (6 hours/day) for one week per year and post treatment OCT macula.

In our study, there was a significant increase in the mean of central macular thickness and superior quadrant of parafovea after part time occlusion treatment compared to pretreatment. No significant difference in average macular thickness, (nasal, temporal, inferior) parafovea, perifovea, RNFL thickness, GCL+ and GCL++ before and after treatment.

Tugcu et al., (2014) studied macular thickness in the amblyopic eyes and reported no difference in macular thickness. Chen et al., (2013) reported no significant thickness difference in any region of the macula. Chun-Hsiu (2018) 


\section{CHANGES IN MACULAR THICKNESS AFTER PART TIME OCCLUSION... ${ }^{121}$}

reported no difference was found in the macular and choroidal thicknesses between the persistent and recovered amblyopic eyes. Huynh et al., (2009) found that both foveal minimum thickness and average foveal thickness were greater in the amblyopic eyes with high myopia than in the normal fellow eyes. In contrast, both inner and outer macular thickness were thinner in the amblyopic eyes compared with that of the fellow eyes. Pang et al., (2015) reported that amblyopic eyes in children with myopic anisometropia had thicker foveae and thinner peripheral maculae compared to the fellow eyes before amblyopia treatment. Central maculae tended to be thinner following amblyopia treatment with no changes in peripheral macula. Kavitha et al., (2019) reported that macular thickness and foveal thickness which were more in amblyopic eyes as compared to normal fellow eyes and normal eyes of normal children, decreased with improvement in BCVA after occlusion therapy. However, there was no difference in RNFL thickness between amblyopic eyes and normal fellow eyes and normal eyes of normal children before and after occlusion therapy.

The variations in results of these reports are probably due to different study populations, defining criteria, type of amblyopia, different instruments used in measuring and co-existent factors like refractive errors.

\section{CONCLUSION}

The mean of central macular thickness and superior quadrant of parapovea increased after part time occlusion treatment compared to pretreatment. No significant difference in average macular thickness, (nasal, temporal, inferior) parapovea, perifovea, RNFL thickness and GCL before and after treatment.

\section{REFERENCES}

1. Bowling B (2016): Kanski's clinical ophthalmology 8th edition, pbl Elsevier USA, chapter 18, strabismus, pp. 737-743.

2. Chen W, Chen J, Huang J, Xu J, Zhang F and Lu F (2013): Comparison of macular and retinal nerve fiber layer thickness in untreated and treated binocular amblyopia. Curr Eye Res., 38:1248-1254.

3. Chun-Hsiu L, Sherine JO, Chung-Ying H, Wei-Chi W, Ling-Yuh K and Meng-Ling Y (2018): Macular Thickness, Foveal Volume, and Choroidal Thickness in Amblyopic Eyes and Their Relationships to the Treatment Outcome. J Ophthalmol.; 2018: 1967621.

4. Huynh SC, Samarawickrama C and Wang XY (2009): Macular and nerve fiber layer thickness in amblyopia: the Sydney Childhood Eye Study. Ophthalmology, 116:1604-1609.

5. Hwang DJ, Kim YJ and Lee JY (2010): Effect and sustainability of part-time occlusion therapy for patients with anisometropic amblyopia aged $\geq 8$ years; British Journal of Ophthalmology, 94:11601164.

6. Kavitha V, Heralgi MM, Harishkumar PD, Harogoppa S, Shivaswamy $\mathrm{H} M$ and Geetha H (2019): Analysis of macular, foveal, and retinal nerve fiber layer thickness in children with unilateral anisometropic amblyopia and their changes following occlusion therapy. Indian J Ophthalmol, 67:1016-22.

7. Liu H, Zhong $L$ and Zhou $X$ (2010): Macular abnormality observed by OCT in children with amblyopia failing to achieve normal visual acuity after long-term treatment. J Pediatr Ophthalmol Strabismus, 47: $17-23$.

8. Pang Y, Frantz KA, Block S, Goodfellow GW and Allison C (2015): Effect of amblyopia treatment on macular thickness in 
eyes with myopic anisometropic amblyopia. Invest Ophthalmol Vis Sci., 56:2677-2683.

9. Sapkota C, Alves S and Pina S (2014): Comparison of macular thickness and volume in amblyopic children using time domain optical coherence tomography. Ophthalmologia, 36:231-236.
10. Tugcu B, Araz-Ersan B and Erdogan ET (2014): Structural and functional comparison of the persistent and resolved amblyopia. Doc Ophthalmol., 128:101-109. 


\section{تغير ات في سمك الماقولة بعد التغطية الجزئية للعين في}

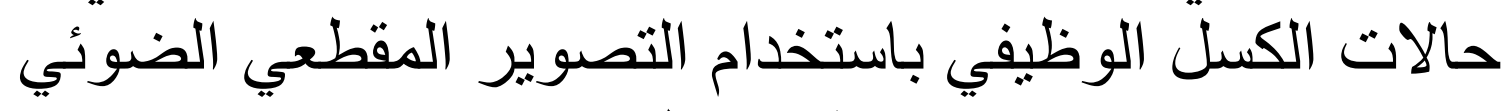
المتر ابط

محمد زكريا عيد، أحمد محمود أمين، محمود السيد محمد سالم

قسم طب وجر احة العيون، كلية الطب (القاهرة)، جامعة الأزهر

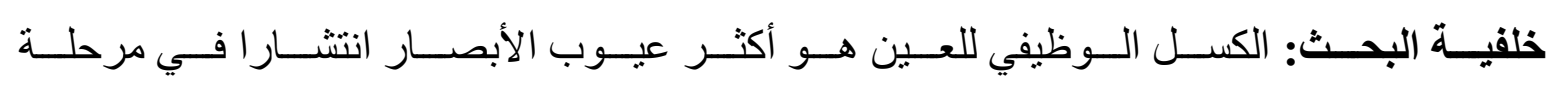

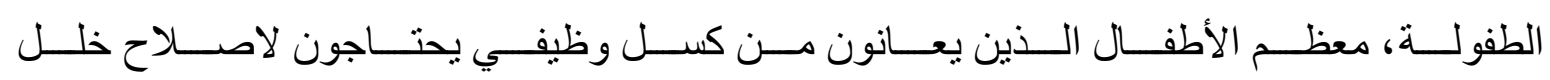

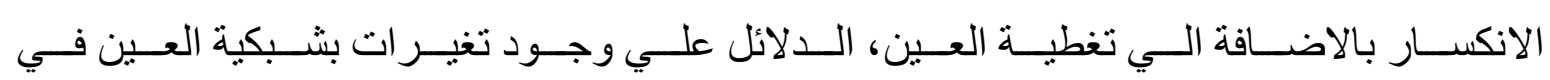
الأعين التي بها كسل وظيفي ماز الت غبر حاسمة و محل جدل.

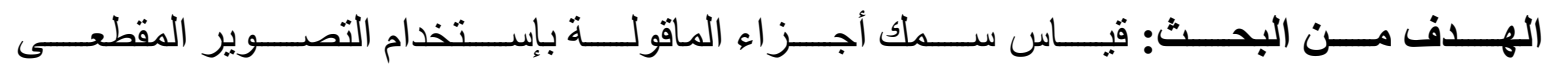

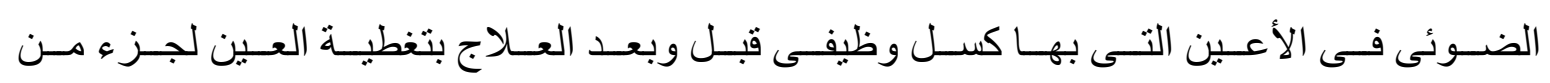
الوقت.

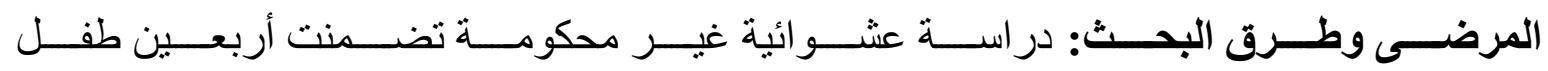

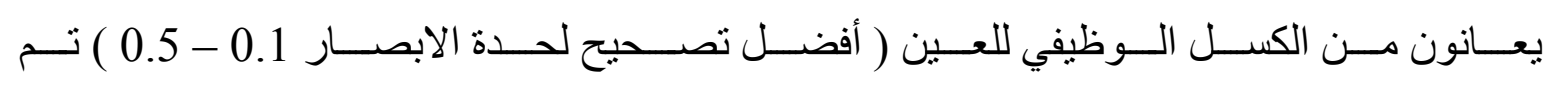

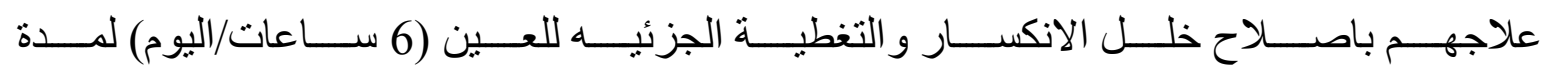

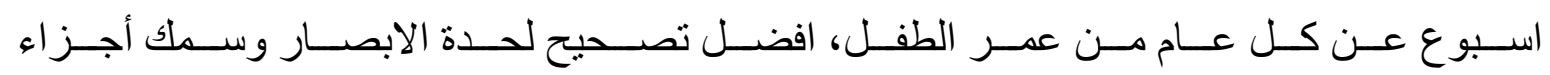

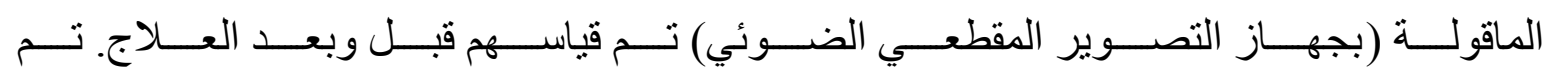

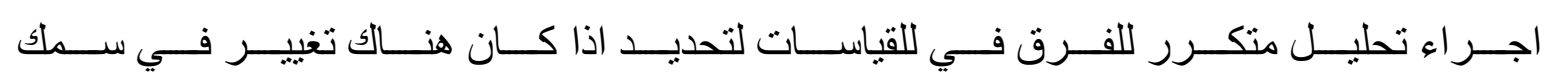
مركز الابصار بعد العلاج.

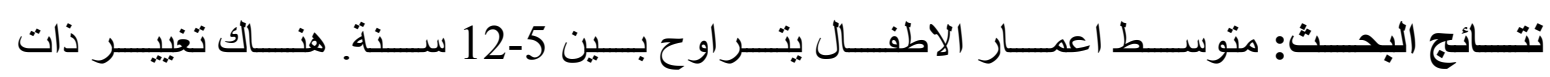

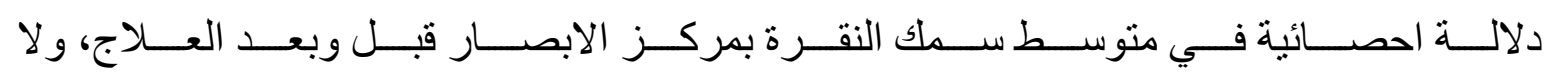
يوجد تغيير ذو دلالة إحصائية في باقي أجزاء ماقولة العين ماعدا الجزء العلوي لألئ

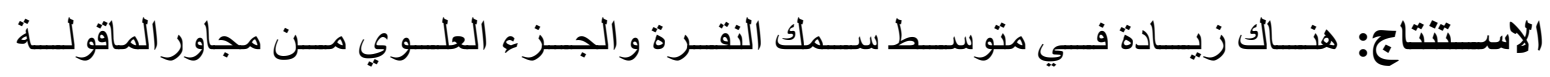

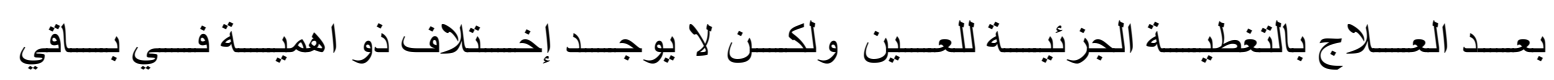




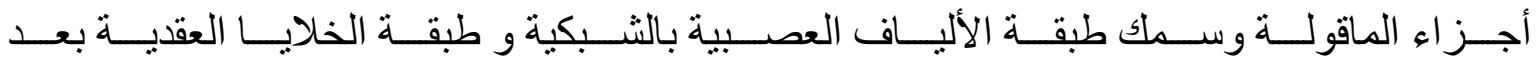
العلاج. 